\title{
Stanley Falkow (1934-2018)
}

\section{Microbe hunter who uncovered how bacteria cause disease.}

$\mathrm{S}$ tanley Falkow discovered the molecular mechanisms through which bacteria cause disease and how to disarm them. But he always described himself as being "on the side of the microbes".

Falkow, who died on 5 May, began his career in the late 1950s, when DNA was first recognized as the stuff of life, and bacteria were thought to be good model systems for studying it. By the 1960s, he had worked out how to extract and isolate the extrachromosomal packets of bacterial DNA that we now call plasmids, and found that these carry information from one microbe to another. This showed how bacteria can acquire the ability to survive on a new food source or become resistant to an antibiotic.

He made the ominous observation that even harmless bacteria could serve as a source of resistance genes for pathogens. Falkow understood the public-health significance of this, predicted the rise of multidrugresistant bacteria and campaigned against the overuse of antibiotics. His discoveries of the molecular nature of antibiotic resistance won him the 2008 Lasker-Koshland Special Achievement Award in Medical Science.

The question that framed Falkow's career was: what is a pathogen? Specifically, what makes some microbes disease agents, while others are innocuous or even beneficial? He hypothesized that bacteria have genes coding for specialized 'virulence factors' - the transferable, molecular equivalents of claws, fangs, toxins, fur and camouflage - that allow pathogenic bacteria to attack, hide and survive in extreme environments. He spent his life identifying the genes and molecules behind these abilities. He discovered, for example, that some bacteria decorate their surfaces with molecules designed to adhere to host cells, and even fool the host into allowing bacteria to invade. Others have molecular needles that disarm white blood cells by injecting proteins that stop the cells moving, or prevent them from sounding the alarm.

Falkow was born the son of Jewish immigrants in Albany, New York, on 24 January 1934 at the peak of the Great Depression. He was a terrible student, especially in mathematics and science, but loved to read. When he was 11 , he found in the local library the book Microbe Hunters by Paul de Kruif. Written for lay audiences in 1926, it describes the personalities and adventures of some of the most important figures in microbiology. Falkow devoured it and decided to become a microbe hunter. His life was a conversation

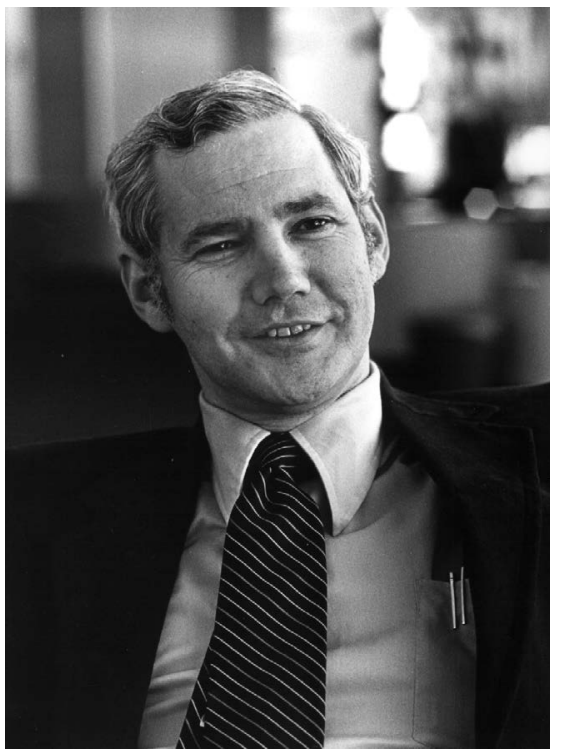

with his heroes from this book.

Microbe Hunters begins with Antonie van Leeuwenhoek, who, in the 1670 s, was the first to craft glass lenses so powerful that he was able to visualize microscopic organisms. When Falkow read this, he had to have a microscope. He found a Gilbert Company Hall of Science microscope on the shelves of the local toy shop (he could not afford it, but in the end, the shop owner gave it to Falkow). Through this, Falkow witnessed the darting shadows of bacteria growing in the spoilt milk that he kept under his bed.

Falkow's love of microscopy continued throughout his career, which started with a $\mathrm{PhD}$ in 1961 from Brown University in Providence, Rhode Island. He learnt electron microscopy and, in the 1970s, at the University of Washington School of Medicine in Seattle, used it to visualize resistance genes that had hopped on to plasmids. In the 1980s at the Rocky Mountain Laboratories in Montana and at Stanford University School of Medicine in California, where he chaired the department of microbiology and immunology, he made micrographs of Yersinia and Salmonella bacteria invading the intestine.

He was the first to make movies with a videomicroscope to show how Salmonella invade gut epithelial cells by causing a literal splash of cytoskeleton and membrane at the cell surface. He adapted diverse methods of painting and tagging molecules inside bacteria and host cells to follow their fate during infection, and even to find bacterial genes that turn on only when inside cells.
Another of Falkow's heroes, Robert Koch, established a set of guidelines in the 1880 s (Koch's postulates) to define when a microbe is responsible for an infection. Falkow extended this idea in the 1980s, developing the 'molecular Koch's postulates'. These describe how one could define virulence at the molecular level - for example by inactivating specific genes to render a microbe harmless, or transferring a gene for adhesion or invasion to an innocuous bacterium to improve its ability to interact with host cells. His lab elucidated the mechanisms of disease of many bacteria (and even yeasts), including major gut pathogens such as Salmonella and pathogenic Escherichia coli, along with bacteria that cause skin, urinary-tract and sexually transmitted infections, whooping cough, pneumonia, sepsis, and even stomach cancer.

Falkow came to think of the "pathogenic lifestyle" as being not about causing disease, but rather about subtly manipulating a host. He became best friends with his prey. Over time, he spoke more and more about the potential beneficial attributes of bacteria that live on and in our body, foreseeing the study of the human microbiome.

Despite his fame, Falkow often said that his greatest achievements were those of his students. One of his most important gifts was his ability to infect these students with the same sense of awe that he had when he first peered into a microscope. More than 120 scientists, including some of today's most prominent microbiologists, were trained in Falkow's laboratory. Despite his illness, he was still teaching at Stanford last semester, and video-calling into classroom discussions and lab meetings.

For pragmatists interested in tools for conquering the microbial world, Falkow's vision provided the technical framework by which to define potential targets for vaccines and methods to identify, fingerprint and follow the evolution of pathogens through molecular epidemiology. For pure biologists, this same vision provided the foundation for understanding the natural history of pathogenic and mutualistic microbes. For those of us who had the good fortune to know him, he left a bounty of stories and examples of his generosity of spirit as a scientist and a mentor.

Manuel R. Amieva is an associate professor of Pediatric Infectious Diseases and of Microbiology \& Immunology at Stanford University School of Medicine; he was one of Falkow's last postdoctoral fellows.

e-mail:amieva@stanford.edu 